\title{
Impact of Endodontic Instrumentation on Surface Roughness of Various Nickel-Titanium Rotary Files
}

\author{
Muhammad Sohail Zafar ${ }^{1,2, \odot}$ \\ ${ }^{1}$ Department of Restorative Dentistry, College of Dentistry, Taibah \\ University, Madinah Al-Munawarah, Saudi Arabia \\ ${ }^{2}$ Department of Dental Materials, Islamic International Dental \\ College, Riphah International University, Islamabad, Pakistan
}

\begin{abstract}
Address for correspondence Muhammad Sohail Zafar, PhD (UK), MSC (UK), FICD (USA), FADI (USA), BDS, Department of Restorative Dentistry, College of Dentistry, Taibah University, Madinah Al-Munawarah 41311, Kingdom of Saudi Arabia (e-mail: drsohail_78@hotmail.com).
\end{abstract}

Eur J Dent 2021;15:273-280

\begin{abstract}
Keywords

- clinical endodontics

- shape memory alloy

- topography

- fatigue resistance

- root canal treatment

- profilometry

Objectives The aim of the present study was to evaluate the surface roughness (SR) of various nickel-titanium (NiTi) rotary endodontic instruments (ProTaper Next [PTN], WaveOne Gold [WOG], and ProTaper Gold [PTG]) before and after root canal instrumentation.

Materials and Methods For each type (PTN, WOG, and PTG), the endodontic instrumentation was performed using extracted mandibular molar teeth's curved mesial root canals (curvature: 20-40 degrees) after determining the working length. Each NiTi file was cleaned, and sterilized following preparation of four root canals and characterized for surface properties before and after endodontic instrumentation using a contact-mode three-dimensional surface profiler. The data were analyzed statistically using Statistical Package for the Social Sciences for SR parameters including average surface roughness value (Sa), root mean square roughness $(S q)$, and peak to valley height (Sz).

Results Preinstrumentation assessment revealed a significant difference for all the three SR variables $(p<0.05)$ for the cutting blade and the flute area. WOG instruments showed the highest SR values $(p=0.000)$. The postinstrumentation assessment revealed significant differences in SR values in the blade and the flute between the three groups $(p<0.05)$, with WOG and PTG exhibiting the highest values in the blade and flute sections, respectively.

Conclusions The SR parameters of intact PTN, WOG, and PTG NiTi files vary and that was increased following the endodontic instrumentation.
\end{abstract}

\section{Introduction}

Root canal shaping is performed using various endodontic files and essentially required for the successful root canal treatment. ${ }^{1}$ In addition to cleaning and shaping, the morphology and original curvature of root canals should be conserved during instrumentation. ${ }^{2}$ The root canals' cleaning and shaping is a technique-sensitive procedure that is vulnerable to complications such as ledge formation, apical transportation, and perforations due to complex root canals anatomy, morphological

published online October 27, 2020
DOI https://doi.org/ 10.1055/s-0040-1718469 ISSN 1305-7456. variations, and over-instrumentation., ${ }^{3,4}$ The nickel-titanium (NiTi) alloy files are more flexible compared with the conventional stainless steel files resulting in an improved quality of root canal preparation and reduced chances of procedural errors. ${ }^{5,6} \mathrm{~A}$ variety of systems and modifications (alloy composition, heat treatments, taper, and cross-sectional design) of NiTi rotary files has been introduced in the recent decades. ${ }^{7-12}$

During endodontic instrumentation, mechanical friction or chemical stimuli may lead to loss of surface contents (wear) and formation of surface defects such as scratches and

(c) 2020. European Journal of Dentistry.

This is an open access article published by Thieme under the terms of the Creative Commons Attribution-NonDerivative-NonCommercial-License, permitting copying and reproduction so long as the original work is given appropriate credit. Contents may not be used for commercial purposes, or adapted, remixed, transformed or built upon. (https://creativecommons.org/licenses/by-nc-nd/4.0/) Thieme Medical and Scientific Publishers Pvt. Ltd., A-12, 2nd Floor, Sector 2, Noida-201301 UP, India 
microcracks. ${ }^{13,14}$ Accordingly, the wear and surface topography of NiTi instruments may be affected in terms of manufacturing, compositional variations, and mechanical stresses. For example, ProTaper Next (PTN) instruments, NiTi alloy is processed thermally during fabrication to enhance flexibility and cyclical fatigue resistance. ${ }^{15}$ PTN instruments have a regressive taper, a rectangular cross-section, and are designed to minimize its contact area with the root canal walls and decrease fatigue stresses while instrumenting root canals. ${ }^{16}$ The WaveOne Gold (WOG) rotary files are manufactured using a heat-treated NiTi alloy (gold wire) to machine a parallelogram-shaped cross-section resulting in improved properties and clinical performance compared with the WaveOne (WO) files that are fabricated using M-wire. ${ }^{17,18}$ In contrast, ProTaper Gold (PTG) instruments have a triangular cross-section, a variable progressive taper (similar to ProTaper Universal), and are known for improved flexibility and cyclic fatigue resistance. ${ }^{19}$

The surface roughness(SR) characterization of NiTi rotary files provides useful information regarding surface defects, performance, and associated limitations. ${ }^{20}$ Therefore, researchers have explored a variety of techniques including scanning electron microscopy (SEM), ${ }^{20,21}$ atomic force microscopy (AFM), ${ }^{22,23}$ and noncontact optical profilometry to study surface morphology of endodontic files. ${ }^{24-26}$ At present, there are no published reports comparing the effects of endodontic cleaning and shaping on surface nano-profiles of PTN, WOG, and PTG rotary endodontic files. Therefore, the aim of this study was to compare the surface profilometry of various NiTi rotary endodontic files (PTN, WOG, and PTG) before and after instrumentation.

\section{Materials and Methods}

\section{Experimental Design and Study Groups}

The present experimental study was approved by the institutional research ethics committee at the College of Dentistry, Taibah University, Madinah Al-Munawarah, Saudi Arabia (Ref: TUCDREC/20200216/MSZahaf). The NiTi rotary endodontic instruments were divided into three study groups $(n=5)$ including PTN, WOG, and PTG. All NiTi rotary instruments used in the present study were manufactured by Dentsply Sirona Endodontics, Tulsa, United States. To rule out any manufacturing defects, the surfaces of all NiTi instruments were inspected using an optical microscope at 50X (Leica DM6000; Leica Microsystems, Wetzlar, Germany). All NiTi instruments were characterized for surface roughness properties before and after endodontic instrumentation.

\section{Root Canal Instrumentation}

The root canal instrumentation was performed on extracted lower molars' curved mesial (mesiobuccal and mesiolingual) root canals (Vertucci type 1; curvature: 20-40 degrees) according to the Schneider's technique. ${ }^{27}$ Briefly, each root canal was explored using stainless steel K-files (size\#10; Dentsply Maillefer, Oklahoma, United States) and the working length was determined at $1 \mathrm{~mm}$ shorter from the apical foramen. Following the manufacturers' instructions, the root canal instrumentation was performed using sodium hypochlorite (3\%: $\sim 5 \mathrm{~mL}$ for each canal) as a root canal irrigant. After the preparation of four root canals, each NiTi file was cleaned using an ultrasonic cleaner, sterilized $\left(134^{\circ} \mathrm{C}\right.$ for $4 \mathrm{~min}$; pressure: $\left.30 \mathrm{psi}\right)$, and dehydrated. A single operator performed all the endodontic instrumentation. Four root canals were prepared using each NiTi instrument (20 canals for each group). Any root canals with pathological conditions (such as internal or external resorption, open apex) or history of endodontic treatment were excluded. In addition, any root canals other than Vertucci type 1 were also excluded.

\section{Surface Profilometry Analysis}

The surface profilometry analysis of NiTi rotary files was performed before and after endodontic instrumentation using a contact-mode surface profiler (Dektak150; Veeco Instruments Inc., Tucson, Arizona, United States) fitted with a low-inertia stylus. Each NiTi file was mounted on a glass slide, and fixed on the sample stage. Using the inbuilt camera, the cutting blade, and adjacent flute area, $3 \mathrm{~mm}$ coronal from the file's tip was chosen and scanned using the fixed parameters (stylus radius $200 \mathrm{~nm}$ : stylus $z$-range $36 \mu \mathrm{m}$; and scan duration $60 \mathrm{sec}$ ). For each NiTi file, five distinct locations (area dimensions: $100 \times 100 \mu \mathrm{m}^{2}$ ) were scanned. The profilometer was operated at a constant stylus force $(4 \mathrm{mg})$, which allowed the stylus to scan and analyze the alloy surface without causing any damages or deformation of the surface. The surface characterization was performed in a standard position as described previously by AlRahabi and Atta ${ }^{12}$ and data were exported and saved for further analysis of SR parameters; also, SR parameters including average surface roughness value ( $\mathrm{Sa}$ ), root mean square roughness (Sq), and peak to valley height (Sz) were determined (ISO 25178-2).

\section{Statistical Analysis}

The surface profilometry data were analyzed statistically using Statistical Package for the Social Sciences software (version 22, IBM Corp., Armonk, New York, United States) with the significance value $(p<0.05)$. The one-way analysis of variance (ANOVA) determined significant differences among SR parameters (Sa, Sq, and $\mathrm{Sz}$ ) before and after endodontic instrumentation. The multiple comparisons between SR values for the three test groups were evaluated by post-hoc Tukey HSD test. Pair-wise comparison of SR parameters before and after the instrumentation was evaluated by paired-samples statistics. The KolmogorovSmirnov test was applied to analyze the normality of data.

\section{Results}

The current study evaluated and compared the SR parameters (Sa, Sq, and Sz) of three endodontic NiTi instruments at their cutting blade and flute areas before and after instrumentation using a contact-mode nanoscale profilometer. Preinstrumentation assessment revealed a significant difference with one-way ANOVA for all the three SR variables $(p<0.05)$ for the cutting blade and the flute between the instruments (-Table 1). The results showed that WOG instruments have the highest values of SR parameters at the blade as well as at the flute locations, which was statistically significant ( $p=0.000$ ) than the groups PTN and PTG. Almost similar SR values for the cutting blade were 
Table 1 The quantitative analysis of surface roughness parameters $(\mu \mathrm{m})$ of tested instruments before root canal instrumentation

\begin{tabular}{|c|c|c|c|c|}
\hline Scanned location & $\mathrm{NiTi}$ instrument & $\begin{array}{l}\mathrm{Sq}^{\mathrm{a}} \\
\text { Mean } \pm \mathrm{SD}\end{array}$ & $\begin{array}{l}\mathrm{Sa}^{\mathrm{a}} \\
\text { Mean } \pm \text { SD }\end{array}$ & $\begin{array}{l}\mathrm{Sz}^{\mathrm{a}} \\
\text { Mean } \pm \text { SD }\end{array}$ \\
\hline \multirow[t]{3}{*}{ Blade } & PTN & $6.61 \pm 1.07$ & $4.25 \pm 1.02$ & $20.80 \pm 1.53$ \\
\hline & WOG & $12.95 \pm 1.08$ & $10.47 \pm 1.04$ & $49.13 \pm 2.43$ \\
\hline & PTG & $5.79 \pm 0.93$ & $4.56 \pm 1.04$ & $38.83 \pm 1.67$ \\
\hline $\begin{array}{l}\text { ANOVA }^{b} \\
p \text {-value }\end{array}$ & & 0.0000 & 0.0000 & 0.0000 \\
\hline \multirow[t]{3}{*}{ Flute } & PTN & $0.34 \pm 0.04$ & $0.30 \pm 0.03$ & $1.56 \pm 0.14$ \\
\hline & WOG & $0.62 \pm 0.12$ & $0.51 \pm 0.11$ & $2.85 \pm 0.63$ \\
\hline & PTG & $0.62 \pm 0.07$ & $0.43 \pm 0.15$ & $4.09 \pm 0.44$ \\
\hline $\begin{array}{l}\text { ANOVA }^{\mathrm{b}} \\
p \text {-value }\end{array}$ & & 0.0000 & 0.0000 & 0.0000 \\
\hline
\end{tabular}

Abbreviations: ANOVA, analysis of variance; NiTi, nickel titanium; PTG, ProTaper Gold; PTN, ProTaper Next; Sa, average surface roughness value; SD, standard deviation; Sq, root mean square roughness; Sz, peak to valley height; WOG, WaveOne Gold.

Note: Scanned areas dimensions: $100 \times 100 \mu \mathrm{m}^{2}$.

The Sq, Sa, Sz were measured in micrometers $(\mu \mathrm{m})$.

'The significance level $(p \leq 0.05)$.

noted for the PTN and PTG, which was statistically nonsignificant $(p=0.252)$, while for the SR of the flute of the PTN and PTG, there were significant differences $(p=0.000)$ between the values.

- Table 2 describes the postinstrumentation SR parameter values for blade and flute of the three tested groups. The postinstrumentation assessment revealed significant differences in the Sq, Sa, and Sz values in the blade and flute between the three groups $(p<0.05)$, with WOG and PTG exhibiting the highest values in the blade and flute section, respectively. The one-to-one comparison between the surface parameters before and after the instrumentation of all the three groups with post-hoc Tukey test is presented in - Table 3 . For most of the comparisons, significant differences were observed except between the PTN and PTG for the blade section before and after the instrumentation ( - Table $\mathbf{3}$ ).

Paired-samples $t$-test was used for the comparison between the SR parameters (Sq, Sa, Sz) of the three tested instruments before and after the instrumentation within the same-group specimens (-Table 4 ). In the blade section for the PTN and WOG, significant differences $(p<0.05)$ were noted for all the three SR parameters, while for the PTG in the blade section, only Sq parameter $(p=0.116)$ was found to be nonsignificant. In the flute section for PTN, significant differences were found for all the three SR parameters, while for the WOG only Sq ( $p$ $=0.022)$ and for PTG only Sa $(p=0.000)$ were found to be significant. The qualitative analysis indicated enhanced SR and wear of all the NiTi instrument (PTN, WOG, and PTG) compared with the corresponding intact instruments. In addition, the NiTi instruments exhibited formation of minor surface scratches, pits, and microcavities without showing any signs of cracks or fractures ( - Fig. 1).

\section{Discussion}

The present study investigated the effects of endodontic instrumentation on different NiTi rotary instruments (PTN,
WOG, and PTG) by comparing the SR before and after instrumentation. The endodontic instrumentation was performed on extracted mandibular molars' curved mesial root canals (curvature: $20-40$ degrees) using the NiTi files and characterized for changes in the SR by a three-dimensional (3D) surface profiler. The NiTi rotary instruments are prone to spontaneous fracture ${ }^{28}$ due to their nature or presence of artifacts (such as fissures and pits) formed during the process of milling during the manufacturing..$^{29}$ The cold working of NiTi alloy results in the formation of work hardening areas that are prone to cracking or brittle fracture without showing any signs of ductile behavior. ${ }^{30}$ The cyclic loading and unloading during instrumentation results in repeated transfiguration between the austenitic and martensitic phases thereby altering the mechanical properties such as fatigue strength. ${ }^{31}$ Although the NiTi rotary instruments have excellent surface smoothness and cyclic fatigue resistance, ${ }^{32}$ the stresses caused by mechanical instrumentation increase the SR, force of friction, and likelihood of instrument failure. ${ }^{33}$ Therefore, understanding the effects of mechanical stresses on SR of NiTi rotary instruments may suggest useful information in terms of surface defects and clinical safety. ${ }^{24}$

Noncontact 3D optical profilometry has analyzed the surface characteristics qualitatively and quantitatively. ${ }^{34,35}$ In case of NiTi instruments, typical metallic properties of metal such as shiny surface and optical properties interfere with the optical scanning therefore affecting the accuracy of data. ${ }^{36}$ The present study evaluated the changes in surface topographies of NiTi rotary files by a stylus profilometry technique through the low-force contact mode and characterized the sensitive surfaces nondestructively. ${ }^{37}$ In addition, stylus profiler has a nanoscale vertical and lateral resolution $(\sim 0.5 \mathrm{~nm}$ and $100 \mathrm{~nm}$ ), respectively, ${ }^{38}$ making it a suitable technique for surface characterization.

In the current study, preinstrumentation assessment revealed a significant difference in the three SR variables $(p<0.05)$ of the cutting blade and the flute between the NiTi instruments. The highest values of SR parameters were 
Table 2 The quantitative analysis of surface roughness parameters $(\mu \mathrm{m})$ of tested instruments following root canal instrumentation

\begin{tabular}{|c|c|c|c|c|}
\hline $\begin{array}{l}\text { Scanned } \\
\text { location }\end{array}$ & $\mathrm{NiTi}$ instrument & $\begin{array}{l}S^{a} \\
\text { Mean } \pm S D\end{array}$ & $\begin{array}{l}\mathrm{Sa}^{\mathrm{a}} \\
\text { Mean } \pm \text { SD }\end{array}$ & $\begin{array}{l}\mathrm{Sz}^{\mathrm{a}} \\
\text { Mean } \pm S D\end{array}$ \\
\hline \multirow[t]{3}{*}{ Blade } & PTN & $7.07 \pm 1.06$ & $5.60 \pm 0.72$ & $29.25 \pm 10.40$ \\
\hline & WOG & $13.82 \pm 1.00$ & $12.24 \pm 1.54$ & $55.82 \pm 4.91$ \\
\hline & PTG & $6.35 \pm 0.52$ & $4.60 \pm 1.03$ & $39.94 \pm 1.78$ \\
\hline $\begin{array}{l}\text { ANOVA }^{b} \\
p \text {-value }\end{array}$ & & 0.000 & 0.000 & 0.000 \\
\hline \multirow[t]{3}{*}{ Flute } & PTN & $0.53 \pm 0.05$ & $0.44 \pm 0.05$ & $2.57 \pm 0.21$ \\
\hline & WOG & $0.77 \pm 0.06$ & $0.66 \pm 0.06$ & $3.38 \pm 0.46$ \\
\hline & PTG & $0.71 \pm 0.09$ & $0.65 \pm 0.11$ & $4.18 \pm 0.42$ \\
\hline $\begin{array}{l}\text { ANOVA }^{\mathrm{b}} \\
p \text {-value }\end{array}$ & & 0.005 & 0.001 & 0.000 \\
\hline
\end{tabular}

Abbreviations: ANOVA, analysis of variance; NiTi, nickel titanium; PTG, ProTaper Gold; PTN, ProTaper Next; Sa, average surface roughness value; SD, standard deviation; Sq, root mean square roughness; Sz, peak to valley height; WOG, WaveOne Gold.

aThe Sq, Sa, Sz were measured in micrometers $(\mu \mathrm{m})$.

'The significance level $(p \leq 0.05)$.

Table 3 Multiple comparisons of the surface roughness parameters of blade and flute area among the tested groups before and after instrumentation

\begin{tabular}{|c|c|c|c|c|c|}
\hline Time & $\begin{array}{l}\text { Dependent } \\
\text { variable }\end{array}$ & $\begin{array}{l}\text { Group } \\
\text { comparisons }\end{array}$ & $\begin{array}{l}\text { Sig. }{ }^{\text {a }} \\
\text { Sq }(\mu \mathrm{m})\end{array}$ & $\begin{array}{l}\text { Sig. }^{a} \\
\text { Sa }(\mu \mathrm{m})\end{array}$ & $\begin{array}{l}\text { Sig. }^{a} \\
\text { Sz }(\mu \mathrm{m})\end{array}$ \\
\hline \multirow{6}{*}{$\begin{array}{l}\text { Before } \\
\text { Instrumentation }\end{array}$} & \multirow[t]{3}{*}{ Blade } & PTN vs WOG & 0.000 & 0.000 & 0.000 \\
\hline & & PTN vs PTG & 0.252 & 0.867 & 0.000 \\
\hline & & WOG vs PTG & 0.000 & 0.000 & 0.000 \\
\hline & \multirow[t]{3}{*}{ Flute } & PTN vs WOG & 0.000 & 0.710 & 0.000 \\
\hline & & PTN vs PTG & 0.000 & 0.000 & 0.000 \\
\hline & & WOG vs PTG & 0.001 & 0.000 & 0.001 \\
\hline \multirow{6}{*}{$\begin{array}{l}\text { After } \\
\text { Instrumentation }\end{array}$} & \multirow[t]{3}{*}{ Blade } & PTN vs WOG & 0.000 & 0.000 & 0.000 \\
\hline & & PTN vs PTG & 0.285 & 0.113 & 0.012 \\
\hline & & WOG vs PTG & 0.000 & 0.000 & 0.000 \\
\hline & \multirow[t]{3}{*}{ Flute } & PTN vs WOG & 0.169 & 0.293 & 0.485 \\
\hline & & PTN vs PTG & 0.003 & 0.001 & 0.000 \\
\hline & & WOG vs PTG & 0.177 & 0.029 & 0.000 \\
\hline
\end{tabular}

Abbreviations: PTG, ProTaper Gold; PTN, ProTaper Next; Sa, average surface roughness value; Sq, root mean square roughness; Sz, peak to valley height; WOG, WaveOne Gold.

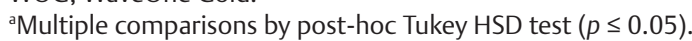

Table 4 Pair-wise comparison of surface roughness parameters before and after the instrumentation by paired-samples $t$-test

\begin{tabular}{|c|c|c|c|c|}
\hline \multirow{2}{*}{$\begin{array}{l}\text { Location } \\
\text { Blade }\end{array}$} & \multirow[t]{2}{*}{ NiTi instrument } & \multicolumn{3}{|c|}{ Comparison of SR values before and after instrumentation ${ }^{a}$} \\
\hline & & $\mathrm{Sq}$ & Sa & Sz \\
\hline & PTN & 0.012 & 0.031 & 0.051 \\
\hline & WOG & 0.001 & 0.000 & 0.000 \\
\hline \multirow[t]{3}{*}{ Flute } & PTG & 0.116 & 0.049 & 0.008 \\
\hline & PTN & 0.006 & 0.036 & 0.001 \\
\hline & WOG & 0.022 & 0.351 & 0.222 \\
\hline
\end{tabular}

Abbreviations: NiTi, nickel titanium; PTG, ProTaper Gold; PTN, ProTaper Next; Sa, average surface roughness value; Sq, root mean square roughness; SR, surface roughness; Sz, peak to valley height; WOG, WaveOne Gold.

aThe comparison is significant at the $p \leq 0.05$ level. 

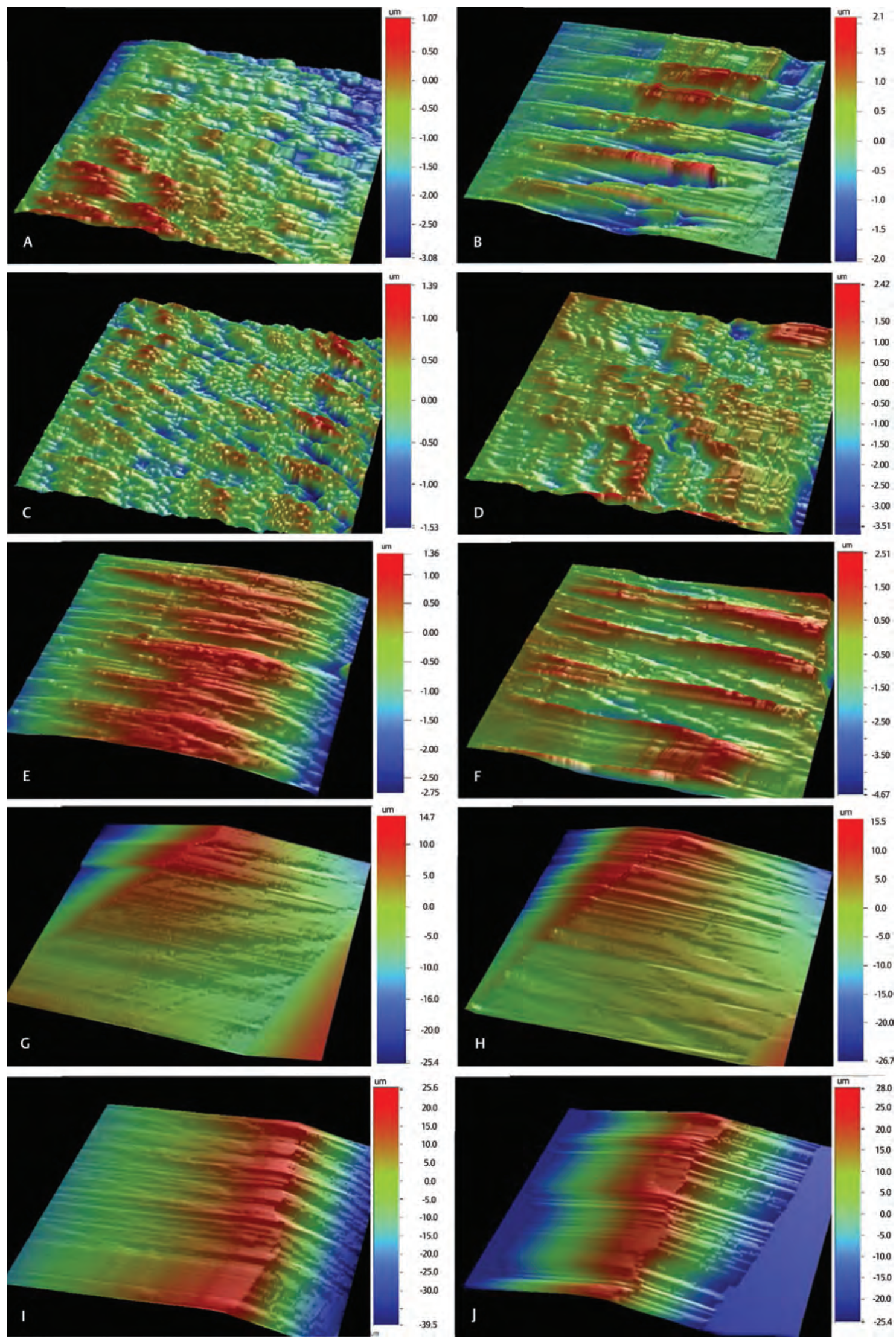

Fig. 1 Qualitatively analysis demonstrating the impact of root canal instrumentation on surface topography of various nickel titanium instruments: (A) ProTaper Next (PTN [flute]) before instrumentation; (B) PTN (flute) after instrumentation; (C) WaveOne Gold (WOG [flute]) before instrumentation; (D) WOG (flute) after instrumentation; (E) ProTaper Gold (PTG [flute]) before instrumentation; (F) PTG (flute) after instrumentation; (G) PTN (blade) before instrumentation; (H) PTN (blade) after instrumentation; (I) WOG (blade) before instrumentation; (J) WOG (blade) after instrumentation. 
recorded for WOG instruments for both cutting blade and flute areas. The differences in the SR values for the cutting blade of PTN and PTG were statistically insignificant. These findings are similar to a recent study ${ }^{12}$ that reported higher SR of intact WO and WOG instruments compared with the Reciproc blue instruments. The SEM analysis of Reciproc and WO instruments' cutting blade also revealed presence of various irregularities on their surface before instrumentation. ${ }^{20}$ Such differences in the preinstrumentation SR are associated with variable material properties' (such as hardness, strength) processing and finishing methods used by manufacturers during the fabrication of endodontic instruments. ${ }^{12}$ For instance, heat treatment used during the manufacturing of certain endodontic instruments (such as WOG) may affect the NiTi surface properties. Firstov et $\mathrm{al}^{39}$ reported the surface characterization of NiTi following heat treatment using various techniques including SEM, X-ray diffraction, thermogravimetry, X-ray photoelectron, and Raman spectroscopies. Additionally, the thermal processing $\left(600-800^{\circ} \mathrm{C}\right)$ alters the surface characteristics of NiTi leading to a rougher or even porous surface. ${ }^{39}$ The manufacturing of WOG files involves heating the alloy followed by gradual cooling down; $4^{0}$ such heat treatments may affect the surface characteristics during instrumentation. The surface porosity of NiTi instrumentation may initiate the crack initiation and ultimately lead to the file fracture. ${ }^{41}$ The AFM analysis of WOG showed a noticeable surface porosity following endodontic instrumentation making them prone to failure. ${ }^{42}$ In addition, such properties may be due to compositional changes as the addition of gold to NiTi alloys reduces surface hardness and affects the associated properties. ${ }^{43}$ Although WOG files are commonly used, ${ }^{42}$ the potential changes in their surface characteristics following instrumentation cannot be overlooked.

In addition to the heat treatment, cold working of instruments (such as grinding, hammering) also affects the microstructure of the alloy by residual stresses in crystal grains and formation of various surface artifacts such as folds and pits. ${ }^{44}$ The manufacturing of endodontic instruments by machining involves grinding of the alloy to get the desired shape and taper. The formation of surface features such as grooves and pits is unavoidable during grinding and machining of NiTi instruments. ${ }^{32}$ The SR of the NiTi instruments particularly the cutting blade influences various mechanical properties related to the clinical performance during the endodontic instrumentation. By increasing the SR, friction between instrument and tooth increases, hence compromising the cutting efficiency, cyclic fatigue strength, and safety. ${ }^{32,33}$ Therefore, such surface defects may potentially lead to the formation of stress concentration areas, crack propagation, and fracture during the clinical use. ${ }^{44,45}$ The machining grooves and pits that are potential areas for stress concentration can be reduced by electropolishing of rotary file surfaces. ${ }^{44}$

In the present study, the postinstrumentation assessment revealed significant differences in the SR values of all instruments compared with the preinstrumentation SR. The highest SR values in the blade and flute sections were observed for WOG and PTG, respectively. A similar study by AlRahabi and
Atta $^{12}$ compared the SR of various NiTi instruments (Reciproc blue, Reciproc, WO, and WOG) before and after instrumentation. The results of the current study are in line with AlRahabi and Atta $^{12}$ as both studies reported an increase in the SR values following endodontic instrumentation. In addition, Özyürek et $\mathrm{al}^{42}$ used AFM to compare the surface topography of WOG and WO and reported comparatively higher surface porosity values in WOG following instrumentation. Various factors that contributed to increasing the NiTi instruments' SR during endodontic working included mechanical or torsional stresses, friction with tooth structure, and chemical corrosion caused by root canal irrigators. For example, the canal enlargement prior to NiTi instrumentation reduces torsional stresses ${ }^{46}$ thereby reducing the associated instrument wear and likelihood of crack formation. In the present study, to mimic the clinical conditions, a glide path was created by a stainless steel K-file (size\#10) to reduce torsional stresses on NiTi instruments. In addition, NiTi instrumentation was performed using sodium hypochlorite irrigator (3\%: $\sim 5 \mathrm{~mL}$ for each canal). Irrigating solutions affect the surface and enhance the SR of NiTi instruments. ${ }^{42}$ Fayyad and Mahran ${ }^{47}$ used AFM to investigate the effects of immersing NiTi in different irrigating solutions. It was reported that $5.25 \%$ sodium hypochlorite increased the SR of various NiTi instruments. ${ }^{47}$ The corrosion resistance of NiTi instruments can be enhanced by various surface treatments such as coating a layer of titanium oxide. ${ }^{48}$ The qualitative analysis of intact instruments showed minor surface grooves ( - Fig. 1A, C, E, G, I) even before endodontic instrumentation. The formation of surface features such as grooves and pits is attributed to machining and grinding of NiTi instruments while yielding desired shape and taper. Therefore, the formation of surface features on NiTi endodontic instruments is unavoidable. ${ }^{32}$ In addition, the qualitative analysis confirmed an increase in the SR and wear of all NiTi instrument following root canal instrumentation mainly due to the formation of pits and microcavities. However, there was no evidence of crack formation or crack propagation in any of the NiTi instruments due to their better cyclic fatigue resistance. The PTN and PTG instruments are manufactured by micro-milling and getting heat treatment. ${ }^{49}$ The sizes and tapers of PTG are similar to that of ProTaper Universal; however, the flexibility and cyclic fatigue resistance are improved corresponding to the Gold thermal treatment. ${ }^{16}$ The PTN instruments having martensitic phase at room temperature ${ }^{50}$ are flexible and better resistant to fatigue fracture..$^{51}$ Although these findings suggested the safety of using NiTi instruments for the root canal instrumentation of up to four canals, varying factors such as torque, canal curvature, angulation, and mechanical stress may have a different outcome.

The present study is the first one to compare the profilometry of PTN, WOG, and PTG rotary instruments at the microscale. It was observed that using NiTi files for the instrumentation of up to four root canals produced no remarkable grooves or cracks on their surface. There are certain limitations; the present study used a contact-mode stylus profiler (stylus diameter of $400 \mathrm{~nm}$ ); thus, the stylus cannot accurately scan any fine grooves that are less than $400 \mathrm{~nm}$. Therefore, further investigations using advanced research techniques such as AFM or white-light 
interferometry would provide additional information about SR at a nanoscale. In terms of endodontics prospective, although the endodontic instrumentation was simulated using natural teeth and irrigation solutions, factors such as inadequate access and angle of instrumentation may alter the mechanical stresses on NiTi instruments. Clinically, the root canals may have a wide range of morphological variations in terms of canal configuration ${ }^{52}$ that may influence the mechanical stresses during instrumentation and surface wear. The present study investigated the effects of endodontic instrumentation on NiTi files while using molars of specific curvature (20-40 degrees) under extra-oral access. The effects of endodontic instrumentation in terms of surface chemistry of NiTi files were not addressed in this study. The elemental analysis may provide useful information regarding changes in the NiTi surface chemistry in response to exposure to irrigators and mechanical stresses. Therefore, future in vitro and clinical studies investigating a wide range of mentioned variable affecting the endodontic instrumentation are required to validate the findings reported in the present study.

\section{Conclusions}

The surface profilometry revealed variations in the SR parameters of intact PTN, WOG, and PTG NiTi files. Although the SR of all NiTi files investigated in the present study was increased following the endodontic instrumentation of four root canals, there were no signs of any fracture or visible defect formation advocating their safe use.

\section{Funding \\ None.}

\section{Conflicts of Interest}

None declared.

\section{Acknowledgments}

The author thanks Drs. Hani Ghabbani, Raghied Atta, and Syed Habib for the technical support and proofreading the manuscript.

\section{References}

1 Schilder H. Cleaning and shaping the root canal. Dent Clin North Am 1974;18(2):269-296

2 González-Rodrguez MP, Ferrer-Luque CM. A comparison of Profile, Hero 642, and $\mathrm{K} 3$ instrumentation systems in teeth using digital imaging analysis. Oral Surg Oral Med Oral Pathol Oral Radiol Endod 2004;97(1):112-115

3 Franco V, Fabiani C, Taschieri S. Malentacca A, Bortolin M, Del Fabbro M. Investigation on the shaping ability of nickel-titanium files when used with a reciprocating motion. J Endod 2011;37(10):1398-1401

4 Alrahabi M, Zafar MS, Adanir N. Aspects of clinical malpractice in endodontics. Eur J Dent 2019;13(3):450-458

5 Lopes HP, Gambarra-Soares T, Elias CN, et al. Comparison of the mechanical properties of rotary instruments made of conventional nickel-titanium wire, M-wire, or nickel-titanium alloy in R-phase. J Endod 2013;39(4):516-520
6 Gutmann JL, Gao Y. Alteration in the inherent metallic and surface properties of nickel-titanium root canal instruments to enhance performance, durability and safety: a focused review. Int Endod J 2012;45(2):113-128

7 Bürklein S, Mathey D, Schäfer E. Shaping ability of ProTaper NEXT and BT-RaCe nickel-titanium instruments in severely curved root canals. Int Endod J 2015;48(8):774-781

8 Zhao D, Shen Y, Peng B, Haapasalo M. Root canal preparation of mandibular molars with 3 nickel-titanium rotary instruments: a micro-computed tomographic study. J Endod 2014;40(11):1860-1864

9 Gekelman D, Ramamurthy R, Mirfarsi S, Paqué F, Peters OA. Rotary nickel-titanium GT and ProTaper files for root canal shaping by novice operators: a radiographic and micro-computed tomography evaluation. J Endod 2009;35(11):1584-1588

10 Gianluca G. The K3 rotary nickel titanium instrument system. Endod Topics 2005;10(1):179-182

11 Thompson SA, Dummer PM. Shaping ability of Hero 642 rotary nickel-titanium instruments in simulated root canals: Part 1. Int Endod J 2000;33(3):248-254

12 AlRahabi AMK, Atta RM. Surface nanoscale profile of WaveOne, WaveOne Gold, Reciproc, and Reciproc blue, before and after root canal preparation. Odontology 2019;107(4):500-506

13 Zhou Z, Zheng J. Tribology of dental materials: a review. Journal of Physics D: Applied Physics 2008;41(11):113001

14 Zheng J, Weng LQ, Shi MY, et al. Effect of water content on the nanomechanical properties and microtribological behaviour of human tooth enamel. Wear 2013;301(1-2):316-323

15 Gao Y, Gutmann JL, Wilkinson K, Maxwell R, Ammon D. Evaluation of the impact of raw materials on the fatigue and mechanical properties of ProFile Vortex rotary instruments. J Endod 2012;38(3):398-401

16 Gagliardi J, Versiani MA, de Sousa-Neto MD, Plazas-Garzon A, Basrani B. Evaluation of the shaping characteristics of ProTaper gold, ProTaper NEXT, and ProTaper universal in curved canals. J Endod 2015;41(10):1718-1724

17 Topçuoğlu HS, Düzgün S, Aktı A, Topçuoğlu G. Laboratory comparison of cyclic fatigue resistance of WaveOne Gold, Reciproc and WaveOne files in canals with a double curvature. Int Endod J 2017;50(7):713-717

18 Adıgüzel M, Capar ID. Comparison of cyclic fatigue resistance of WaveOne and WaveOne gold small, primary, and large instruments. J Endod 2017;43(4):623-627

19 Arias A, Singh R, Peters OA. Torque and force induced by ProTaper universal and ProTaper next during shaping of large and small root canals in extracted teeth. J Endod 2014;40(7):973-976

20 Hanan AR, Meireles DAd, Sponchiado Júnior EC, Hanan S, Kuga MC, Bonetti Filho I. Surface characteristics of reciprocating instruments before and after use-a SEM analysis. Braz Dent J 2015;26(2):121-127

21 Caballero H, Rivera F, Salas H. Scanning electron microscopy of superficial defects in Twisted files and Reciproc nickel-titanium files after use in extracted molars. Int Endod J 2015;48(3):229-235

22 Yamazaki-Arasaki A, Cabrales R, Santos Md, Kleine B, Prokopowitsch I. Topography of four different endodontic rotary systems, before and after being used for the 12th time. Microsc Res Tech 2012;75(1):97-102

23 Pirani C, Paolucci A, Ruggeri O, et al. Wear and metallographic analysis of WaveOne and reciproc NiTi instruments before and after three uses in root canals. Scanning 2014;36(5):517-525

24 Uslu G, Özyürek T, Yılmaz K. Comparison of alterations in the surface topographies of HyFlex $\mathrm{CM}$ and HyFlex EDM nickel-titanium files after root canal preparation: a three-dimensional optical profilometry study. J Endod 2018;44(1):115-119 
25 Ferreira F, Barbosa I, Scelza P, et al. A new method for the assessment of the surface topography of NiTi rotary instruments. Int Endod J 2017;50(9):902-909

26 Ferreira FG, Barbosa IB, Scelza P, et al. Noncontact three-dimensional evaluation of surface alterations and wear in NiTi endodontic instruments. Braz Oral Res 2017;31:e74

27 Schneider SW. A comparison of canal preparations in straight and curved root canals. Oral Surg Oral Med Oral Pathol 1971;32(2):271-275

28 Peters OA, Roehlike JO, Baumann MA. Effect of immersion in sodium hypochlorite on torque and fatigue resistance of nickel-titanium instruments. J Endod 2007;33(5): 589-593

29 Parashos P, Messer HH. Rotary NiTi instrument fracture and its consequences. J Endod 2006;32(11):1031-1043

30 Kuhn G, Jordan L. Fatigue and mechanical properties of nickel-titanium endodontic instruments. J Endod 2002; 28(10):716-720

31 Miyai K, Ebihara A, Hayashi Y, Doi H, Suda H, Yoneyama T. Influence of phase transformation on the torsional and bending properties of nickel-titanium rotary endodontic instruments. Int Endod J 2006;39(2):119-126

32 Lopes HP, Elias CN, Vieira MV. Vieira VT, de Souza LC, Dos Santos AL. Influence of surface roughness on the fatigue life of nickel-titanium rotary endodontic instruments. J Endod 2016;42(6):965-968

33 Nair AS, Tilakchand M, Naik BD. The effect of multiple autoclave cycles on the surface of rotary nickel-titanium endodontic files: an in vitro atomic force microscopy investigation. J Conserv Dent 2015;18(3):218-222

34 Alrahabi M, Zafar MS, Ahmed N. Effects of handpiece speed on the performance of undergraduate dental students in preclinical training. J Taibah Univ Med Sci. 2015;10(1):50-55

35 Zafar MS, Ahmed N. The effects of acid etching time on surface mechanical properties of dental hard tissues. Dent Mater J 2015;34(3):315-320

36 Vorburger TV, Rhee H, Renegar TB, Song J, Zheng A. Comparison of optical and stylus methods for measurement of surface texture. Int J Adv Manufact Technol. 2007;33(1-2):110-118

37 Poon CY, Bhushan B. Comparison of surface roughness measurements by stylus profiler, AFM and non-contact optical profiler. Wear 1995;190(1):76-88

38 Anonymous [Internet]. Veeco. veeco ships 500th dektak 150 surface profiler. 2009 [cited]. Available at: https://ir.veeco. com/news-events/press-releases/press-release-details/2009/ Veeco-Ships-500th-Dektak-150-Surface-Profiler/default.aspx
39 Firstov GS, Vitchev RG, Kumar H. Blanpain B, Van Humbeeck J. Surface oxidation of NiTi shape memory alloy. Biomaterials 2002;23(24):4863-4871

40 Özyürek T. Cyclic fatigue resistance of reciproc, WaveOne, and WaveOne gold nickel-titanium instruments. J Endod 2016;42(10):1536-1539

41 Alapati SB, Brantley WA, Svec TA, Powers JM, Nusstein JM, Daehn GS. SEM observations of nickel-titanium rotary endodontic instruments that fractured during clinical use. J Endod 2005;31(1):40-43

42 Özyürek T, Yılmaz K, Uslu G, Plotino G. The effect of root canal preparation on the surface roughness of WaveOne and WaveOne Gold files: atomic force microscopy study. Restor Dent Endod 2018;43(1):e10

43 De-Deus G, Silva EJ, Vieira VT, et al. Blue thermomechanical treatment optimizes fatigue resistance and flexibility of the reciproc files. J Endod 2017;43(3):462-466

44 Kuhn G, Tavernier B, Jordan L. Influence of structure on nickel-titanium endodontic instruments failure. J Endod 2001;27(8):516-520

45 Kim HC, Kwak SW, Cheung GS, Ko DH, Chung SM, Lee W. Cyclic fatigue and torsional resistance of two new nickel-titanium instruments used in reciprocation motion: Reciproc versus WaveOne. J Endod 2012;38(4):541-544

46 Shen Y, Haapasalo M, Cheung GS, Peng B. Defects in nickel-titanium instruments after clinical use. Part 1: relationship between observed imperfections and factors leading to such defects in a cohort study. J Endod 2009;35(1):129-132

47 Fayyad DM, Mahran AH. Atomic force microscopic evaluation of nanostructure alterations of rotary NiTi instruments after immersion in irrigating solutions. Int Endod J 2014;47(6):567-573

48 Trépanier C, Tabrizian M, Yahia LH, Bilodeau L, Piron DL. Effect of modification of oxide layer on NiTi stent corrosion resistance. J Biomed Mater Res 1998;43(4):433-440

49 Gavini G, Santos MD, Caldeira CL, et al. Nickel-titanium instruments in endodontics: a concise review of the state of the art. Braz Oral Res 2018;32(suppl 1) :44-65.

50 Pereira ES, Gomes RO, Leroy AM, et al. Mechanical behavior of M-Wire and conventional NiTi wire used to manufacture rotary endodontic instruments. Dent Mater 2013;29(12):e318-e324

51 Pereira ESJ, Amaral CC, Gomes JACP, Peters OA, Buono VTL, Bahia MGA. Influence of clinical use on physical-structural surface properties and electrochemical potential of NiTi endodontic instruments. Int Endod J 2018;51(5):515-521

52 Alrahabi M, Sohail Zafar M. Evaluation of root canal morphology of maxillary molars using cone beam computed tomography. Pak J Med Sci 2015;31(2):426-430 